\title{
TEORES DE NITROGÊNIO NO SOLO E NAS FRAÇÕES DA MATÉ RIA ORGÂNICA SOB DIFERENTES SISTEMAS DE PRODUÇÃO DE MILHO(1)
}

\author{
W. J . O. SOUZA(2) \& W. J . MELO(3)
}

\begin{abstract}
RESUMO
Com o objetivo de avaliar o efeito de sistemas de produção sobre a dinâmica do $\mathbf{N}$ no solo e nas frações da matéria orgânica, realizou-se, por seis anos, em J aboticabal (SP), um experimento constituído de: semeadura convencional de milho com pousio no inverno (C-Mi-P), plantio direto de milho e pousio no inverno (D-Mi-P), plantio convencional de milho em rotação com soja e pousio no inverno (C-Mi-P-So), plantio direto de milho em rotação com soja e pousio no inverno (D-Mi-P-So) e plantio direto de milho com uso de Mucuna aterrina (mucunapreta), Cajanus cajan (feijão guandu) e Crotalaria juncea no inverno (D-Mi-Mu, D-Mi-Gu e D-Mi-Cr), em delineamento de blocos ao acaso e parcelas subdivididas. Após 60 dias da emergência das plântulas, coletaram-se amostras de solo (0-0,05, 0,05-0,10 e 0,10-0,20 m) e planta. Nas amostras de terra, avaliaram-se os teores de $\mathrm{N}$ total, $\mathrm{N}-\mathrm{NH}_{4}{ }^{+}, \mathrm{N}-\mathrm{NO}_{3}{ }^{-}, \mathrm{N}$ biomassa microbiana ( $\left.\mathrm{N}-\mathrm{B}\right), \mathrm{N}$ potencialmente mineralizável (NPM), N total nas frações: matérias húmicas (MH), solúvel em água (FSA), ácido fúlvico (AF), ácido húmico (AH) e humina (HN) com dados expressos em base de TFSE. Nas folhas, determinaram-se os teores de $\mathbf{N}$ total, e nas plantas de adubo verde (semeadas após a colheita do milho), mediram-se a produção de matéria seca (MS). Observaram-se valores maiores de NPM na camada de 0-0,05 m e nos tratamentos com plantio direto, envolvendo ou não rotação de culturas ou adubação verde, com a FSA se comportando de modo semelhante. $O$ sistema de cultivo convencional, envolvendo ou não rotação de culturas, proporcionou maiores valores de $\mathbf{N}$ mineral na camada de $0,05-0,10 \mathrm{~m}$, em razão da presença de maiores valores de $\mathbf{N}$-nítrico. $\mathbf{O}$ cultivo convencional acelerou o processo de mineralização do $\mathrm{N}$, enquanto a maior adição de matéria orgânica pela cultura de inverno no sistema de plantio direto promoveu incremento da fração potencialmente mineralizável do $\mathbf{N}$ no solo.
\end{abstract}

Termos de indexação: milho, plantio direto, adubação verde, ácido fúlvico, ácido húmico, humina

\footnotetext{
(1) Parte da Tese de Mestrado do primeiro autor. Recebido para publicação em dezembro de 1999 e aprovado em junho de 2000.

(2) Doutorando na F aculdade de Ciências Agrárias eVeterinárias, Universidade Estadual Paulista - UNESP, Campus deJ aboticabal. Via de Acesso Prof. Paulo Donato Castellane, s/n, CEP 14.870-000 J aboticabal (SP). E-mail: souzaw@etsite.com.br

(3) Professor Titular do Departamento de Tecnologia da Faculdade de Ciências Agrárias e Veterinárias, UNESP.
} 


\title{
SUMMARY: NITROGEN IN SOIL AND SOIL ORGANIC MATTER FRACTIONS AFFECTED BY DIFFERENT CORN PRODUCTION SYSTEMS
}

\begin{abstract}
A long-term field trial was carried-out in J aboticabal (SP) to estimate the effect of production systems on soil nitrogen and soil organic matter fractions. Thetreatments tested were corn in conventional sowing in summer and no tillage in winter (C-Mi-P), maize in direct sowing in summer and no tillagein winter (D-Mi-P), maizein direct sowing in summer, Mucuna aterrina as green manurein winter (D-Mi-Mu), maizein direct sowing in summer, Cajanus cajan as green manure in winter (D-Mi-Gu), maize in conventional sowing in summer, no tillage in winter and soybean in next summer (C-Mi-P-So), maize in direct sowing in summer, notillagein winter and soybean in next summer (D-Mi-P-So) and maize in direct sowing in summer, and Crotalaria juncea as green manure in winter (D-Mi-Cr). The experimental design was randomized blocks with four replicates. Following 60 days after plant emergence, soil (0-0.05, 0.05-0.10 and 0.10-0.20 m depth) and plants weresampled. In the soil samples, the fol lowing forms of nitrogen were determinated: total- $\mathrm{N}$, nitrate-N, ammoni um- $\mathrm{N}$, mi crobial biomass $\mathrm{N}$, humic matter, fulvic acid, humic acid and humin $\mathrm{N}$. Soil organic matter potential of mineralization was al so estimated. $\mathrm{N}$ content was evaluated in the maizeleaves and green and dried weight determined in thewinter crops, which were collected when $50 \%$ of theplants werefl owering. Nitrogen mineralization potentially higher values were obtained in the 0-0.05 m layer and under direct sowing with or without crop rotation or green manurein thewinter. Similar results wereobtained for thehumic acid $\mathrm{N}$. Conventional sowing with or without crop rotation showed higher mineral $\mathrm{N}$ values in the 0.05-0.10 $\mathrm{m}$ layer, with higher values for nitrate-N. Conventional sowing increased $\mathrm{N}$ mineralization and direct sowing caused a larger input of organic matter and potentially mineralizablenitrogen.
\end{abstract}

Index terms: maize, direct sowing, green manure, fulvic acid, humic acid, humin.

\section{NTRODUÇÃO}

A degradação dos solos inicia-se com a remoção da vegetação natural e acentua-se com os cultivos subseqüentes, removendo matéria orgânica e nutrientes quenão são repostos na mesma proporção ao longo do tempo. Em dado momento, os níveis de nutrientes podem-se tornar tão baixos que inviabilizam a produção agrícola, caracterizando um estádio avançado da degradação.

O nitrogênioéum dos principais fatores limitantes aoaumento ou mesmoà manutençãoda produtividade das culturas nos solos tropicais, pela sua dinâmica complexa e custo da obtenção na indústria, o que leva à busca dealternativas viáveis para minimizar a necessidade de aplicação e prol ongar o seu tempo de disponibilidade para as plantas.

O uso de sistemas conservacionistas, que englobam adubação verde, rotação de culturas e plantio direto, é capaz de proporcionar isto, com elevações nos teores de nitrogênio total nas camadas superficiais do solo, redução de perdas via imobilização por mi crorganismos eliberação gradual do nutriente (Anderson \& Domsch, 1980; Amado et al ., 1999). I sto decorre do tipo equalidade do material adicionado à superfície, da seqüência de culturas adotada (Mengel, 1996), da forma de cultivar o solo e do tempo de adoção destas práticas. Os resíduos liberam carbono, nitrogênio e outros componentes simples duranteo processo de decomposição, dos quais parte retorna à atmosfera na forma de gás $\left(\mathrm{CO}_{2}\right.$, $\mathrm{NH}_{3}$, etc.), parteéimobilizada pelos microrganismos decompositores, parte permanece na forma prontamente disponível para as plantas e o restante é perdido por lixiviação ou direcionado à produção de substâncias húmicas (Stevenson, 1985).

Mudanças no sistema de cultivo refletem na biomassa microbiana do solo, que responde por grande parte da dinâmica de decomposição do material orgânico. Quando há pouca mobilização do solo, existea tendência de menor disponibilidade de $\mathrm{N}$ pela redução da mineralização dos resíduos vegetais e aumento da imobilização pela biomassa microbiana (Vargas \& Scholles, 1998). A quantidade de nutrientes de plantas retida nos tecidos microbianos, atingindo $2,5 \%$ do carbono total e $5 \%$ do nitrogênio total do solo (Anderson \& Domsch, 1980), representa considerável fração do nitrogênio facilmente mineralizável, que, junto com açúcares, aminoácidos e ácidos alifáticos, compõe o N potencialmente mineralizável do solo (Schnier et al., 1987; Mengel, 1996).

Em aproximadamente três meses, os tecidos microbianos decompõem-se, liberando nitrogênio na forma assimilável (Anderson \& Domsch, 1980; Paul $\&$ Clark, 1989). 
Os microrganismos também são importantes na formação de substâncias húmicas, seja pela síntese de produtos (Tate III, 1987) e de enzimas que catalisam processos de polimerização, seja pela partici pação em etapas de processos que ocorrem em múltiplos estádios atéà formação deácido húmicoe fúlvico (Stevenson, 1985).

Pelo exposto, o presente trabalho teve como objetivo avaliar os efeitos causados por diferentes sistemas de produção de milho sobre as formas de nitrogênio do solo, das frações da matéria orgânica e da produção de matéria seca pelas plantas de cobertura do solo durante o outono e inverno.

\section{MATE RIAL E MÉTODOS}

O trabal ho foi realizado na área experimental da Fazenda de Ensino e Pesquisa da Faculdade de Ciências Agrárias e Veterinárias, da UNESP, Campus de J aboticabal (SP), localizada a uma altitude de 610 metros e com as seguintes coordenadas geográficas: $21^{\circ} 15^{\prime} 22^{\prime \prime} \mathrm{S}$ e $48^{\circ} 15^{\prime} 18^{\prime \prime} \mathrm{W}$. O clima é do tipo Cwa, segundo a classificação de Köppen, isto é, subtropical, temperado, seco no inverno, temperatura média máxima superior a $22^{\circ} \mathrm{C}$ e pluviosidade entre $100 \mathrm{~mm}$ (no inverno) e $1.500 \mathrm{~mm}$ (no verão). O solo é um Latossolo Roxo fase argilosa, cujas características químicas antes da instalação do experimento encontram-se no quadro 1.

\section{Histórico da área}

Ano agrícola 1992/93: foi feita a calagem com 2 t ha-1 de cal cário dol omítico, seguindo-seincorporação por meio de gradagem e uma subsolagem para el iminar camada decompactação. A cultura do mil ho (híbrido BRASKALB 678) foi semeada em espaçamento de 0,90 $0,15 \mathrm{~m}$, com adubação no sulco de $120 \mathrm{~kg} \mathrm{ha}^{-1}$ da fórmula 2-20-10. A cobertura nitrogenada e potássica foi feita com $480 \mathrm{~kg} \mathrm{ha}^{-1}$ de sulfato de amônio e $94 \mathrm{~kg} \mathrm{ha}^{-1}$ decloreto de potássio (Raij et al., 1985). O controle de plantas invasoras foi realizado mecanicamente.

\section{Instalação dos tratamentos nos anos subseqüen- tes}

Nas parcelas destinadas à semeadura convencional, foram feitas uma aração com arado de discos e duas gradagens com gradeniveladora hidráulica. Foi realizado o controle de plantas daninhas com cultivador mecânico. Nas parcelas destinadas à semeadura direta, utilizaram-se: herbicida sistêmico (Glifosate na dose de 3,5 L ha-1), sempre 15 a 20 dias antes da semeadura de verão para o controle das ervas daninhas estabelecidas na área durante o período de pousio, e herbicida de contato (Paraquat na dose 3,0 L ha-1), antes da instalação da cultura de inverno. Na semeadura, utilizou-se semeadora especial para o sistema plantio direto, a qual revolve o solo somente na linha de semeadura, enquanto o controle de plantas daninhas foi realizado com aplicação de herbicida em pós-inicial ou pós-média, (para o milho ou soja), dependendo das condições do ambiente no momento da aplicação. O quadro 2 mostra o esquema de culturas e o histórico da área experimental.

Em todos os anos, o milho (e, ou, a soja) foi semeado entre os meses de outubro e a primeira quinzena de dezembro, dependendo das condições de umidade do solo e numa profundidade de 0,05$0,08 \mathrm{~m}$ aproximadamente, já que o experimento foi realizado sem irrigação.

Delineamento experimental etratamentos: 0 experimento foi instalado em parcelas com $80 \mathrm{~m}^{2}$, no delineamento de blocos ao acaso, em parcelas subdi vididas, com setetratamentos (Quadro 2), como parcelas, três profundidades de amostragem (0-0,05, 0,05-0,10 e 0,10-0,20 m), como subparcelas, equatro repetições.

\section{Amostragem de solo}

As amostras deterra foram retiradas 60 dias após a emergência das plântulas, no momento da diagnose foliar do milho, coletando-se uma subamostra na linha e uma na entrel inha (cincolinhas por parcela), que foram juntadas, homogeneizadas, colocadas em sacos de pol ietil eno e transferidas rapidamente para caixa de isopor com gelo. O material coletado foi levado para o laboratório, onde parte das amostras

Quadro 1. Características químicas do solo $(0-0,20 \mathrm{~m})$ pouco antes da instalação do experimento na área

\begin{tabular}{|c|c|c|c|c|c|c|c|c|c|}
\hline pH em $\mathrm{CaCl}_{2}$ & M.o. & P resina & K & $\mathrm{Ca}$ & Mg & $\mathbf{H}+\mathbf{A l}$ & SB & $\mathbf{T}$ & $\mathbf{v}$ \\
\hline & $\mathrm{g} \mathrm{dm}^{-3}$ & $\mathrm{mg} \mathrm{dm}^{-3}$ & $\ldots$ & 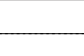 & $-\mathrm{mn}$ & $\mathrm{dm}^{-3}$ & 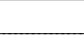 & - & $\%$ \\
\hline 5,9 & 34,0 & 41,0 & 4,1 & 48,0 & 20,0 & 22,0 & 72,1 & 94,1 & 77 \\
\hline
\end{tabular}

Análise realizada no Laboratório de Fertilidade do Solo, do Departamento de Solos e Adubos da FCAV/UNESP, Campus de J aboticabal (SP). 
Quadro 2. Histórico da instalação do experimento ao longo de cinco anos consecutivos em Latossolo Roxo

\begin{tabular}{|c|c|c|c|c|c|c|c|c|c|c|}
\hline \multirow{3}{*}{ Tratamento } & \multirow{3}{*}{$\begin{array}{l}\text { Sistema de } \\
\text { semeadura }\end{array}$} & \multicolumn{9}{|c|}{ Histórico dos anos agrícolas do experimento } \\
\hline & & \multicolumn{2}{|c|}{ 1993/94(1) } & \multicolumn{2}{|c|}{ 1994/95 } & \multicolumn{2}{|c|}{ 1995/96 } & \multicolumn{2}{|c|}{$1996 / 97$} & \multirow{2}{*}{$\begin{array}{c}\text { 1997/98(2) } \\
\text { Verão }\end{array}$} \\
\hline & & Verão & Inverno & Verão & Inverno & Verão & Inverno & Verão & Inverno & \\
\hline C-Mi-P & Convencional & $\mathrm{Mi}$ & $\mathrm{P}$ & $\mathrm{Mi}$ & $P$ & $\mathrm{Mi}$ & $P$ & $\mathrm{Mi}$ & $\mathrm{P}$ & $\mathrm{Mi}$ \\
\hline D-Mi-P & Plantio direto & $\mathrm{Mi}$ & $\mathrm{P}$ & $\mathrm{Mi}$ & $\mathrm{P}$ & $\mathrm{Mi}$ & $P$ & $\mathrm{Mi}$ & $\mathrm{P}$ & $\mathrm{Mi}$ \\
\hline D-Mi-Mu & Plantio direto & $\mathrm{Mi}$ & $\mathrm{Mu}$ & $\mathrm{Mi}$ & $\mathrm{Mu}$ & $\mathrm{Mi}$ & $\mathrm{Mu}$ & $\mathrm{Mi}$ & $\mathrm{Mu}$ & $\mathrm{Mi}$ \\
\hline D-Mi-Gu & Plantio direto & $\mathrm{Mi}$ & Av & $\mathrm{Mi}$ & Av & $\mathrm{Mi}$ & $A v$ & $\mathrm{Mi}$ & $\mathrm{Gu}$ & $\mathrm{Mi}$ \\
\hline C-Mi-P-So & Convencional & $\mathrm{Mi}$ & $\mathrm{P}$ & So & $\mathrm{P}$ & $\mathrm{Mi}$ & $\mathrm{P}$ & So & $\mathrm{P}$ & $\mathrm{Mi}$ \\
\hline D-Mi-P-So & Plantio direto & $\mathrm{Mi}$ & $P$ & So & $\mathrm{P}$ & $\mathrm{Mi}$ & $\mathrm{P}$ & So & $\mathrm{P}$ & $\mathrm{Mi}$ \\
\hline $\mathrm{D}-\mathrm{Mi}-\mathrm{Cr}$ & Plantio direto & $\mathrm{Mi}$ & $\mathrm{Lb}$ & $\mathrm{Mi}$ & $\mathrm{Lb}$ & $\mathrm{Mi}$ & $\mathrm{MI}$ & $\mathrm{Mi}$ & $\mathrm{Cr}$ & $\mathrm{Mi}$ \\
\hline
\end{tabular}

(1) O milho híbrido utilizado neste ano foi o CARGI LL 505, substituído pelo AG 122 nos anos seguintes. (2) a semeadura de inverno ocorreu após a amostragem de terra, cujos resultados de análise são apresentados neste trabalho; $\mathrm{C}=$ sistema de semeadura convencional; $\mathrm{D}=$ sistema de plantio direto; $\mathrm{Mi}=$ milho semeado no verão; So = soja semeada no verão; $\mathrm{P}=$ pousio no inverno; $\mathrm{Mu}=$ semeadura de mucuna-preta (Mucuna aterrina) no espaçamento de 0,45 x 0,20 m (70 kg ha-1 de semente), no inverno; $\mathrm{Gu}=$ semeadura de feijão guandu (Cajanus cajan) no espaçamento de 0,45 x 0,20 m ( $25 \mathrm{~kg} \mathrm{ha}^{-1}$ de semente), no inverno; $\mathrm{Cr}=$ semeadura de Crotalaria juncea no espaçamento de $0,45 \times 0,20 \mathrm{~m}$ ( $25 \mathrm{~kg} \mathrm{ha}^{-1}$ de semente), no inverno; $\mathrm{Av}=$ aveia preta (Avena Strigosa) no espaçamento de 0,45 × 0,05 m (70 kg ha-1 de semente), Lb = lablab (Dolichos Labab) no espaçamento de 0,45 x 0,10 m (70 $\mathrm{kg} \mathrm{ha}^{-1}$ de semente), $\mathrm{Ml}=$ milheto (Peninsetum thiphoides) no espaçamento de $0,45 \times 0,05 \mathrm{~m}$ (70 kg ha-1 de semente).

foi passada em peneira de $2,0 \mathrm{~mm}$ de malha e armazenada em câmara fria para avaliar os teores de nitrogênio da biomassa microbiana. O restante de cada amostra foi col ocado em bandejas e secas ao ar por três dias. Após a secagem, as amostras foram destorroadas, passadas em peneira de $2 \mathrm{~mm}$ (TFSA) earmazenadas em sacos de polietilenoatéa realização das demais análises químicas e bioquímicas.

\section{Amostragem de plantas no momento da diagno- se foliar}

As amostras de planta foram retiradas segundo Trani et al. (1983), coletando-se a folha +4 de dez plantas por parcela, 60 dias após a emergência das plântulas. O material foi levado para o laboratório, onde as fol has foram lavadas com solução de detergente diluído, água de torneira, água destilada eágua dei onizada. Após isto, o material foi levado a uma estufa com circulação forçada de ar e mantido a $60-70^{\circ} \mathrm{C}$ até obtenção de peso constante, após o que foi moído em moinho tipo Willey com peneira de 40 meshes earmazenado em saquinhos de papel até o momento das análises.

\section{Amostragem deadubo verde e plantas daninhas no inverno}

As amostras de adubo verde e de plantas daninhas foram coletadas em 19/08/97, utilizandose um quadro de metal com $1 \mathrm{~m}^{2}$ de área. $O$ quadro foi lançado al eatoriamente sobre as parcelas, coletando-se as plantas presentes em seu interior, que foram levadas ao laboratório, lavadas, secas em estufa com circulação forçada de $\operatorname{ar}\left(60-70^{\circ} \mathrm{C}\right)$ e pesadas (MS) após atingirem peso constante. Nas parcelas com plantas de adubo verde, as plantas daninhas também foram coletadas e pesadas, separadamente. Os dados obtidos foram transformados em toneladas por hectare de matéria seca produzida, separando-seas plantas utilizadas como adubo verde e plantas daninhas.

\section{Análises químicas, bioquímicas e biológicas nas amostras de terra}

$\mathrm{Na}$ extração do nitrogênio da biomassa microbiana, empregou-se o método de fumigaçãoextração, como descrito em Vance et al. (1987), cujo princípio baseia-se na fumigação de amostras de terra mediante utilização de clorofórmio isento de álcool, com o objetivo de promover a morte e "lise" das células microbianas. O teor de nitrogênio da biomassa microbiana do solo foi quantificado, empregando-se o método descrito por B rookes et al. (1985). Pela diferença entre o N extraído em amostras fumigadas e não fumigadas, calculou-se o teor de nitrogênio contido na biomassa microbiana, adotando-se o coeficiente de mineralização $\mathrm{K}_{\mathrm{EN}}=0,54$ (Brookes et al., 1985).

O N total foi determinado na TFSA pelo método de Kjeldahl, descrito em Melo (1977). Para determinar os teores de $\mathrm{N}$-amoniacal eN-nitrato nas amostras de terra, empregou-se o método proposto por Bremner \& Keeney (1965). 
O N potencialmentemineralizável foi determinado mediante o emprego do método proposto por Waring \& Bremner (1964) e descrito em Keeney (1982), incubando-se as amostras de solo em condições anaeróbicas a $40^{\circ} \mathrm{C}$ por um período de sete dias, seguida de extração do $\mathrm{N}-\mathrm{NH}_{4}{ }^{+}$com solução de $\mathrm{KCl}$ $2 \mathrm{~mol} \mathrm{~L}^{-1}$ e destilação a vapor. A quantidade de $\mathrm{N}$ potencialmente mineralizavel foi obtida pela diferença entre os resultados do $\mathrm{N}$-amoniacal no solo antes e depois da incubação.

Para avaliar a qualidade da matéria orgânica nas amostras de terra, utilizou-se o método de extração e fracionamento das matérias húmicas com hidróxido de sódio, descrito em Dabin (1971) e modificado por Duarte (1994), em que a matéria orgânica do solo é fracionada qualitativamente por meio da solubilidade em meio alcalino e ácido, determinando-se os teores de nitrogênio nas frações obtidas. A extração inicial foi realizada com água, obtendo-se a fração solúvel neste meio (FSA); a adição de um agente alcalino originou uma fração solúvel em álcali, denominada matérias húmicas $(\mathrm{MH})$, e um resíduo chamado de humina $(\mathrm{HN})$. Quando acidificada, a fração MH produz uma fração insolúvel em meioácido, ácidos húmicos $(\mathrm{AH})$, euma fração solúvel neste meio, ácidos fúlvicos $(A F)$. A determinação do $\mathrm{N}$ total nas frações FSA, $\mathrm{MH}, \mathrm{AH}$, AF e HN seguiu o mesmo princípio já descrito para a determinação do $\mathrm{N}$ total nas amostras de terra ou de planta, exceto pelo fato de que nas frações da matéria orgânica, excluindo-se a HN, utilizou-se $5 \mathrm{~mL}$ de solução do extrato obtido no fracionamento. $O$ teor de nitrogênio total no $A F$ foi obtido pela diferença entre $\mathrm{N}$ total na $\mathrm{MH}$ e $\mathrm{N}$ total no $\mathrm{AH}$ e, na fração HN, pela diferença entre o teor de $N$ total na terra seca em estufa (TSE) e na MH +FSA.

\section{Análises químicas nas amostras de folha}

As determinações deN total nas amostras foliares foram realizadas no extrato de digestão com ácido sulfúrico, segundo Malavolta et al. (1997).

Os dados obtidos foram analisados estatisticamente pelo teste $F$, aplicando-se o teste de Tukey para comparação de médias (1 e 5\%), com desdobramento dos graus de liberdade nos casos em que houve interação significativa (Pimentel Gomes, 1978).

\section{RESULTADOS E DISCUSSÃO}

Considerando as médias para tratamentos (Quadros 3e4), os valores de N-amoniacal revelaram que, de modo geral, o solo dos tratamentos $\mathrm{D}-\mathrm{Mi}-\mathrm{Cr}$ e D-Mi-Gu tiveram teores significativamente superiores de N-N $\mathrm{H}_{4}{ }^{+}$aos encontrados no do D-Mi$\mathrm{P}$. Da mesma forma, o maior valor de $\mathrm{N}$ potencialmentemineralizável (NPM) foi encontrado no tratamento D-Mi-Cr, significativamente superior aos encontrados nos tratamentos que envolvem cultivo convencional (C-Mi-P-So e C-Mi-P).

Em relação às médias para as profundidades de amostragem (Quadros 3 e 4), os val ores de N Total, $\mathrm{N}$-Biomassa, $\mathrm{N}-\mathrm{NH}_{4}{ }^{+}$e NPM foram, de forma geral, mais el evados na camada de 0-0,05 m, diferindo dos das demais profundidades. Os valores de $\mathrm{N}$ total encontrados nas matérias húmicas (Quadro 4) foram, em geral, superiores na camada mais profunda $(0,10-0,20 \mathrm{~m})$, superando significativamente o valor encontrado na camada de 0-0,05 m.

Comportamento semelhante foi observado em relação aos valores de $\mathrm{N}$ total nos ácidos fúlvicos (AF), tendo a camada de 0-0,05 m apresentado o menor valor médio entre as profundidades.

Os teores de $\mathrm{N}$ total na fração solúvel em água comportaram-se de forma inversa, com seus val ores decrescendo com o aumento da profundidade. $O$ valor encontrado na camada de 0-0,05 m foi, em geral, significativamente maior que o observado nas camadas de 0,05-0,10 e 0,10-0,20 m. Os valores de $\mathrm{N}$ total na TSE (Quadro 3) eN total na humina $(\mathrm{HN})$, apresentados no quadro 4, tiveram comportamento semel hante, mas o teor na camada de 0-0,05 m foi significativamente maior que nas demais camadas.

\section{Formas minerais de $\mathbf{N}$ e $\mathbf{N}$ potencialmente mineralizável}

Estudando o $\mathrm{N}$ potencialmente mineralizável (NPM), foram detectadas diferenças significativas entre os tratamentos, profundidades e interação deles (Figura 1). As diferenças entre tratamentos foram encontradas somente na profundidade de 0 0,05 m, tendo sido o NPM encontrado no tratamento $\mathrm{D}-\mathrm{Mi}-\mathrm{Cr}$ significativamente maior que o dos tratamentos C-Mi-P, C-Mi-P-So, D-Mi-P eD-Mi-P-So. Uma possível explicação para este comportamento éa quantidade ea qualidade do material adicionado à superfície do sol o no período de inverno. O cultivo de leguminosas como adubo verde no inverno anterior propiciou a adição de maior quantidade de fitomassa à superfície (Figura 6). A conseqüência disto é uma atividade microbiana mais intensa, já que grande parte dos tecidos das leguminosas contém proteínas, aminoácidos, ácidos nucléicos e outros materiais facilmente decomponíveis (Mengel, 1996).

O uso do sistema convencional de cultivo, envolvendo ou não rotação de culturas (C-Mi-P-So e C-Mi-P), proporcionou menores valores de NPM, significativamentediferentes dos demais tratamentos na camada de 0-0,05 m. I sto pode ser explicado, em parte, pela decomposição mais acelerada nestes tratamentos, decorrente do ataque mais intenso dos mi crorganismos ao material orgânico incorporado e mineralização do $\mathrm{N}$ em período mais curto. 
Quadro 3. Teores médios de $\mathbf{N}$ total $\left(\mathrm{g} \mathrm{kg}^{-1}\right.$ de TSE), $\mathbf{N}$ da biomassa microbiana ( $\left.\mathrm{N}-\mathrm{B}\right), \mathrm{N}$ amoniacal $\left(\mathrm{N}-\mathrm{NH}_{4}{ }^{+}\right), \mathrm{N}$ nítrico $\left(\mathrm{N}-\mathrm{NO}_{3}^{-}\right)$e $\mathrm{N}$ potencialmente mineralizável (NPM), em $\mathrm{mg} \mathrm{kg}^{-1} \mathrm{de} \mathrm{TSE}^{-1}$, considerando os tratamentos e profundidades de amostragem em um Latossolo Roxo cultivado com diferentes sistemas de produção por seis anos

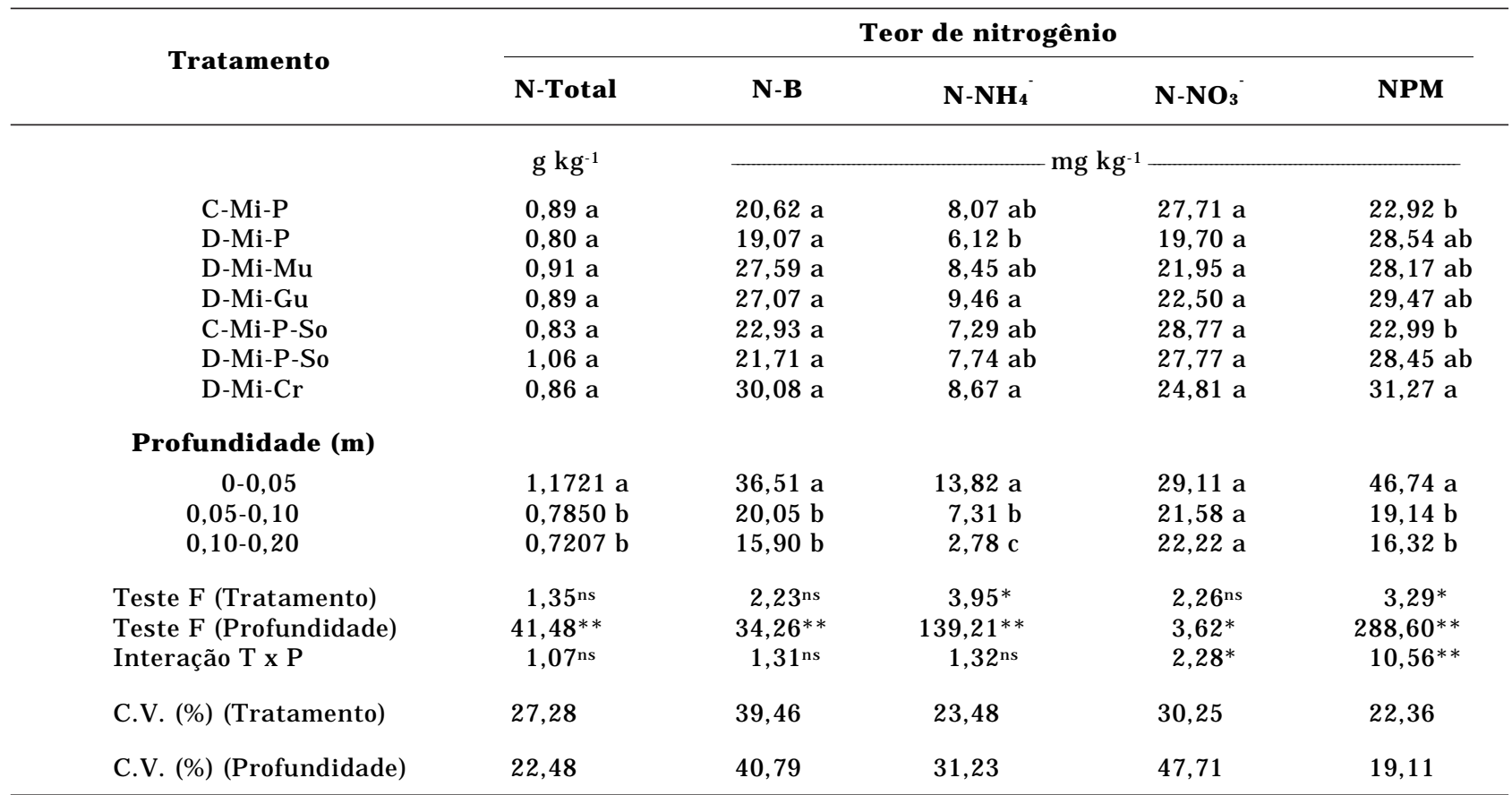

Médias seguidas de mesma letra não diferem entre si pelo teste de Tukey, a $5 \%$. ${ }^{\text {ns }}$, * e**: não-significativo, significativos a 5 e $1 \%$, respectivamente.

Quadro 4. Teores médios de $\mathbf{N}$ total nas matérias húmicas (N-MH), na fração solúvel em água (N-FSA), ácido fúlvico (N-AF), ácido húmico (N-AH) e humina (N-HN), dadas em mg kg-1 de TSE, considerando os tratamentos e profundidades de amostragem em um Latossolo Roxo cultivado com diferentes sistemas de produção por seis anos

\begin{tabular}{|c|c|c|c|c|c|}
\hline \multirow{2}{*}{ Tratamento } & \multicolumn{5}{|c|}{ Teor de nitrogênio } \\
\hline & $\mathbf{N}-\mathbf{M H}$ & N-FSA & N-AF & N-AH & $\mathbf{N}-\mathbf{H N}$ \\
\hline & & & $-\mathrm{mg} \mathrm{kg}^{-1}$ & & \\
\hline $\begin{array}{l}\text { C-Mi-P } \\
\text { D-Mi-P } \\
\text { D-Mi-Mu } \\
\text { D-Mi-Gu } \\
\text { C-Mi-P-So } \\
\text { D-Mi-P-So } \\
\text { D-Mi-Cr }\end{array}$ & $\begin{array}{l}171,39 a \\
174,86 a \\
166,56 a \\
170,76 \mathrm{a} \\
166,01 \mathrm{a} \\
174,37 \mathrm{a} \\
168,75 \mathrm{a}\end{array}$ & $\begin{array}{l}3,30 a \\
3,08 a \\
3,89 a \\
2,73 a \\
2,08 a \\
3,37 a \\
3,27 a\end{array}$ & $\begin{array}{r}99,30 \mathrm{a} \\
93,18 \mathrm{a} \\
89,36 \mathrm{a} \\
92,94 \mathrm{a} \\
101,01 \mathrm{a} \\
102,72 \mathrm{a} \\
92,94 \mathrm{a}\end{array}$ & $\begin{array}{l}79,87 a \\
81,68 \mathrm{a} \\
77,20 \mathrm{a} \\
77,83 \mathrm{a} \\
65,80 \mathrm{a} \\
71,65 \mathrm{a} \\
75,81 \mathrm{a}\end{array}$ & $\begin{array}{l}723,32 a \\
628,80 a \\
745,82 a \\
719,28 a \\
666,83 a \\
883,02 a \\
690,95 a\end{array}$ \\
\hline \multicolumn{6}{|l|}{ Profundidade (m) } \\
\hline $\begin{array}{r}0-0,05 \\
0,05-0,10 \\
0,10-0,20\end{array}$ & $\begin{array}{l}159,47 \mathrm{~b} \\
173,10 \mathrm{ab} \\
178,60 \mathrm{a}\end{array}$ & $\begin{array}{l}4,80 \mathrm{a} \\
3,03 \mathrm{~b} \\
1,48 \mathrm{c}\end{array}$ & $\begin{array}{r}85,70 \mathrm{~b} \\
99,56 \mathrm{a} \\
102,51 \mathrm{a}\end{array}$ & $\begin{array}{l}76,94 \text { a } \\
74,05 \text { a } \\
76,08 \text { a }\end{array}$ & $\begin{array}{r}1007,85 \mathrm{a} \\
608,86 \mathrm{~b} \\
540,76 \mathrm{~b}\end{array}$ \\
\hline $\begin{array}{l}\text { Teste F (Tratamentos) } \\
\text { Teste F (Profundidade) } \\
\text { Interação T x P }\end{array}$ & $\begin{array}{l}0,12^{\text {ns }} \\
5,63^{* *} \\
0,93^{\text {ns }}\end{array}$ & $\begin{array}{c}1,98^{\mathrm{ns}} \\
47,51^{* *} \\
2,01^{*}\end{array}$ & $\begin{array}{l}0,54^{\text {ns }} \\
6,42^{* *} \\
1,24^{\text {ns }}\end{array}$ & $\begin{array}{l}0,91^{\text {ns }} \\
0,43^{\text {ns }} \\
1,75^{\text {ns }}\end{array}$ & $\begin{array}{r}1,58^{\text {ns }} \\
46,22^{* *} \\
1,15^{\text {ns }}\end{array}$ \\
\hline C.V. (\%) (Tratamentos) & 20,66 & 45,03 & 24,62 & 25,91 & 30,79 \\
\hline C.V. (\%) (Profundidade) & 12,89 & 41,08 & 19,55 & 15,83 & 27,31 \\
\hline
\end{tabular}




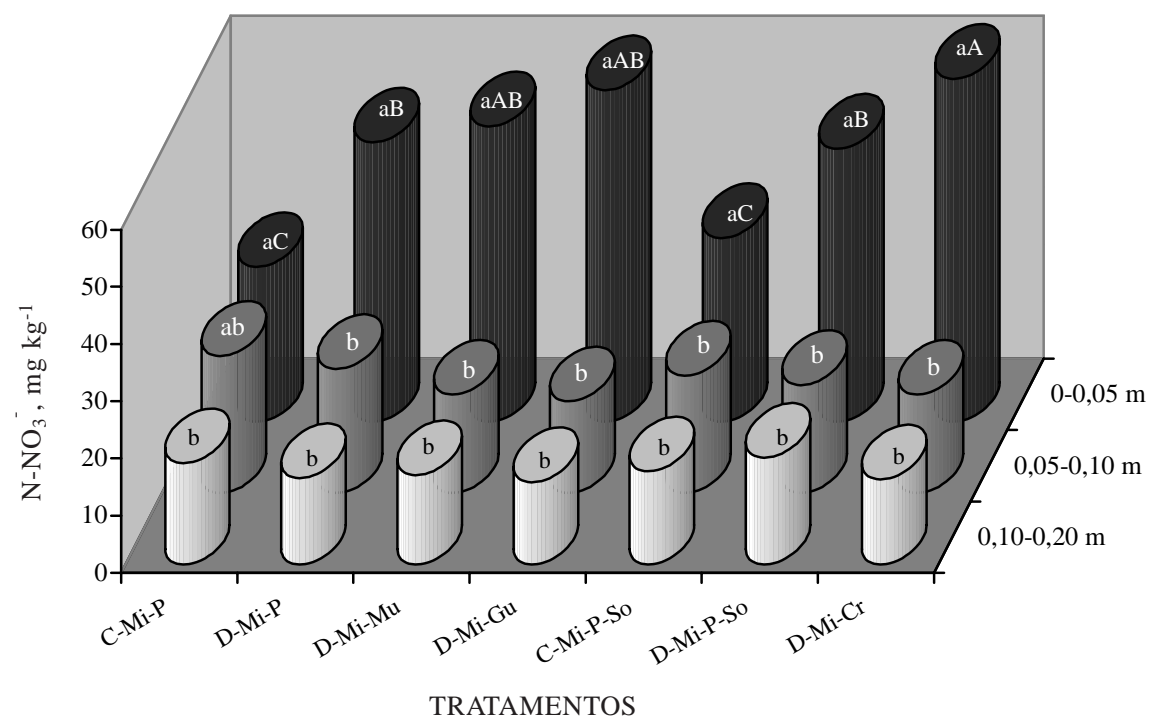

Figura 1. Nitrogênio potencialmente mineralizável em um L atossolo Roxo cultivado em diferentes sistemas de produção por seis anos consecutivos. Letras maiúsculas comparam valores entre tratamentos e letras minúsculas, entre profundidades. $C=$ sistema de semeadura convencional; $D=s i s t e m a$ de plantio direto; $\mathrm{Mi}=$ milho semeado no verão; So = soja semeada no verão; $\mathbf{P}=$ pousio no inverno; $\mathrm{Mu}$ = semeadura de mucuna-preta no inverno; Gu = semeadura de feijão guandu no inverno; $\mathrm{Cr}=$ semeadura de Crotalaria juncea no inverno.

O fato de se alterar apenas o sistema de plantio da cultura (C-Mi-P para D-Mi-P) foi suficiente para elevar em mais de $80 \%$ o NPM. Esta diferença foi reduzida para aproximadamente $48 \%$, quando se incluiu no esquema de cultivo a rotação de culturas (C-Mi-P-So eD-Mi-P-So), provavel mente pela adição de $\mathrm{N}$ via fixação biológica, permitindo que o cultivo convencional de milho em rotação com soja acumulasse maior quantidade de NPM em relação à monocultura do milho no mesmo sistema.

O maior NPM foi observado na camada de 0$0,05 \mathrm{~m}$, decrescendo com oaumento da profundidade, concordando com o encontrado por Salcedo et al. (1985) eAlves et al. (1999), quetambém verificaram redução do NPM das camadas superficiais para as mais profundas. Em todos os tratamentos, observaram-se diferenças significativas entre as camadas de 0-0,05 e 5-10, 0-0,05 e 0,10-0,20 m, mas não entre as duas mais profundas, exceto para o tratamento C-Mi-P, ondea diferença foi significativa apenas entre as camadas 0-0,05 e 0,10-0,20 m. O revolvimento do solo, por provocar a mistura mais íntima do solo com os restos culturais, principalmente na camada de 0-0,10 m, decorrente de operações de gradagem, causa aceleração na decomposição do material orgânico, fato que explicaria os resultados obtidos no tratamento CMi-P.

O nitrogênio da biomassa microbiana (N-B) representou entre 2 e $4 \%$ ou mais do nitrogênio total presente na camada de 0-0,05 m (Quadro 3), decrescendo com a profundidade, até representar menos de $1 \%$ nas camadas mais profundas, conforme otratamento utilizado. Nos tratamentos D-M i-Gu e $\mathrm{D}-\mathrm{Mi}-\mathrm{Cr}$ e na camada superficial $(0-0,05 \mathrm{~m})$, o N-B representou 3,98 e 4,15\% do $\mathrm{N}$ total do solo (Quadro 3), equivalendo a quase o dobro do val or da mesma fração, obtido no tratamento com monocultura convencional de milho (C-Mi-P). Anderson \& Domsch (1980) e Schnier et al. (1987) também estudaram a importância do N-B na composição do N total do solo, quando encontraram resultados semel hantes.

É importante observar (Figura 1) que a percentagem de NPM na mesma camada $(0-0,05 \mathrm{~m})$ acompanhou o comportamento da biomassa microbiana, com o cultivo de feijão guandu e Crotaraia juncea no inverno, chegando a representar aproximadamente $5 \%$ do $\mathrm{N}$ total presente no solo. Dados semel hantes foram obtidos por Garz \& Chaanim (1990), citados por Mengel (1996), mostrando que, após um longo período de incubação, apenas 5 a $6 \%$ do $\mathrm{N}$ total do solo tornou-se potencialmente mineralizável. I sto reforçaria a tese de que a maior parte do NPM do solo é oriundo da biomassa microbiana, quando da decomposição e "lise" de suas células (Schnier et al., 1987), sendo, por isto, tão importante como fonte de nutrientes. Segundo o mesmo autor, o material orgânico adicionado ao solo é mais importante como fornecedor de alimentos para os microrganismos, na 
síntese de novas células, do que como fornecedor direto deN inorgânico liberado de seus teci dos, ainda que isto ocorra em pequenas proporções.

A análise dos dados de $\mathrm{N}$-nítrico no solo, apresentados na figura 2, revelou diferenças significativas entre os tratamentos na profundidade de 0,05-0,10 m, entre as profundidades e a interação deles. Os tratamentos nos quais se utilizou o sistema convencional (C-Mi-P e C-Mi-P-So) apresentaram teores mais el evados de $\mathrm{N}-\mathrm{NO}_{3}{ }^{-}$na profundidade de 0,05-0,10 m. O tratamento C-Mi-P foi o que apresentou omaior val or, superando significativamente os valores encontrados em todos os tratamentos que envolveram o sistema plantio direto, com sucessão ou rotação de culturas. Este val or também representou diferenças significativas entre as profundidades, deixando claro o efeito do preparo do sol o sobre a disponibilidade de $\mathrm{N}-\mathrm{NO}_{3}{ }^{-}$.

O revolvimento do solo expõe os resíduos culturais a um ataque mais intenso dos microrganismos, acel erando a decomposição do material orgânico ea nitrificação do nitrogênio, razão pela qual se observaram elevados teores de $\mathrm{N}-\mathrm{NO}_{3}{ }^{-}$nesta camada.

Este nitrogênio fica à disposição da planta, contribuindo para sua nutrição, já quea amostragem foi realizada num momento de intensa absorção de nutrientes (florescimento). Todavia, a ocorrência de chuvas no mês da col eta (fevereiro) é uma constante na região de J aboticabal (SP), o que facilitaria as perdas de nitrato via lixiviação.

Quando se utilizou o sistema plantio direto, independentemente da adoção ou não de rotação ou sucessão de culturas, os val ores foram mais el evados na camada de 0-0,05 m (Vargas \& Scholles, 1998) (exceto para D-Mi-Gu), ainda que não-significativos (Figura 2). Isto seria um indicativo de que ocorre um processo muito mais lento, porém constante, de mineralização do N orgânico, principalmente daquele presente na forma de $\mathrm{N}$ protéico, aminoácidos, bases nitrogenadas, peptídeos eaminoaçúcares (Mengel, 1996).

\section{N nas frações da matéria orgânica}

Os teores de $\mathrm{N}$ total na fração solúvel em água (FSA), ilustrados na figura 3, apresentaram diferenças significativas entretratamentos somente na camada de 0-0,05 m, onde o manejo C-Mi-P-So apresentou valores inferiores aos dos tratamentos com cultivo de mucuna-preta ou feijão guandu no invernoanterior (D-Mi-Mu eD-Mi-Gu, respectivamente). I sto poderia ser explicado pela maior adição de material orgânico à superfície do solo pelos adubos verdes (Figura 6), evidenciando a facilidade de decomposição de parte de seus componentes em compostos mais simples.

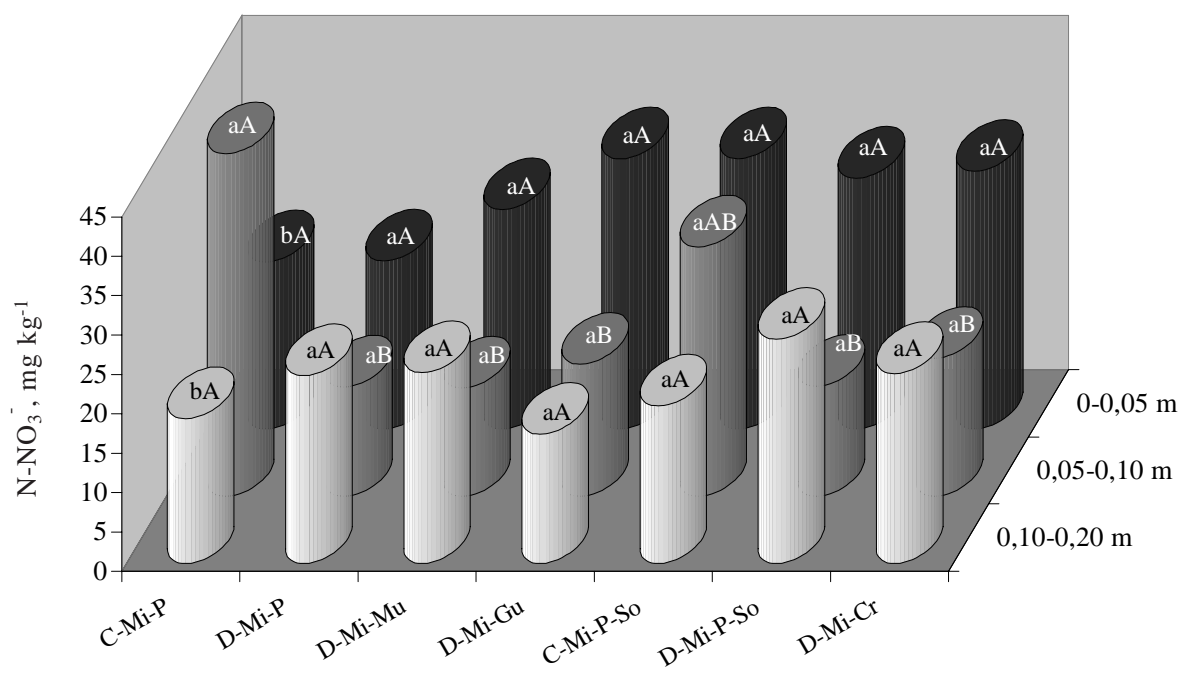

TRATAMENTOS

Figura 2. Nitrogênio nítrico em um Latossolo Roxo cultivado em diferentes sistemas de produção por seis anos consecutivos. Letras maiúsculas comparam valores entre tratamentos e letras minúsculas, entre profundidades. $\mathbf{C}=$ sistema de semeadura convencional; $\mathbf{D}=$ sistema de plantio direto; $\mathrm{Mi}=$ milho semeado no verão; So = soja semeada no verão; $\mathbf{P}=$ pousio no inverno; Mu = semeadura de mucuna-preta no inverno; Gu =semeadura de feijão guandu no inverno; $\mathrm{Cr}=$ semeadura de Crotalaria juncea no inverno. 


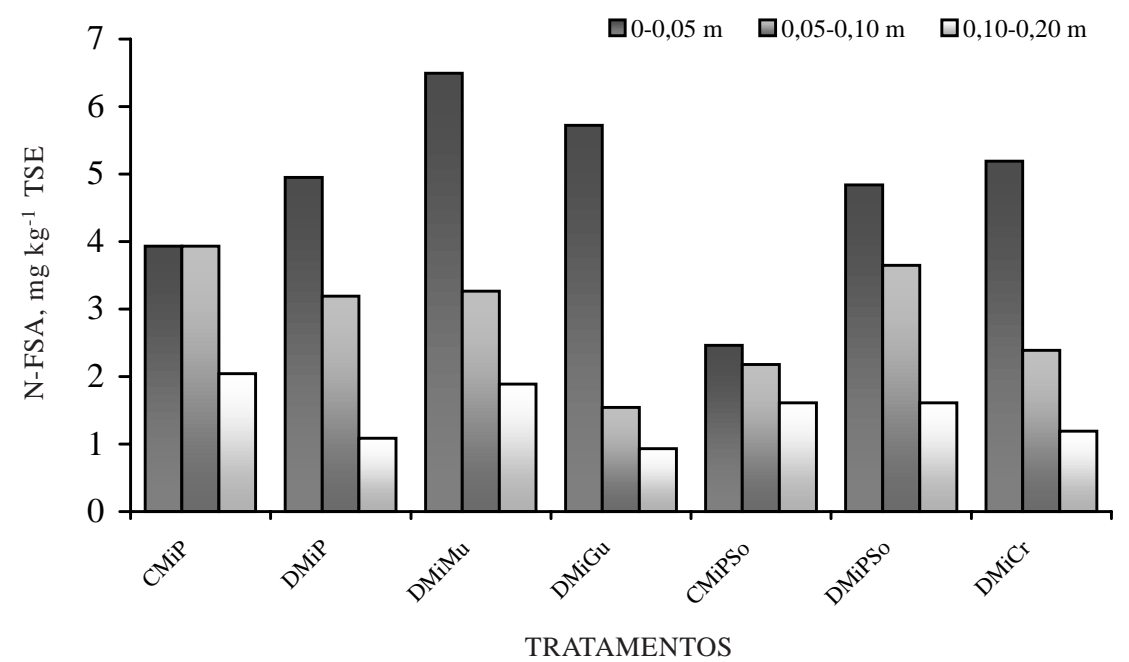

Figura 3. Valores de $\mathbf{N}$ total na fração solúvel em água (FSA) da matéria orgânica, em um Latossolo Roxo cultivado com diferentes sistemas de produção por seis anos consecutivos. $C=$ sistema de semeadura convencional; $\mathrm{D}=$ sistema de plantio direto; $\mathrm{Mi}=$ milho semeado no verão; So $=$ soja semeada no verão; $\mathbf{P}=$ pousio no inverno; $\mathrm{Mu}=$ semeadura de mucuna-preta no inverno; $\mathbf{G u}=$ semeadura de feijão guandu no inverno; $\mathrm{Cr}=$ semeadura de Crotalaria juncea no inverno.

É possível que a maior parte do nitrogênio total extraído pela água esteja em formas prontamente assimiláveis ou em compostos próximos delas, como proteínas, ácidos nucléicos e outros, que também podem ser usados como fonte de energia pelos microrganismos, graças à quantidade limitante de carbono presente nestas plantas. Este fato é de relevada importância na dinâmica do $\mathrm{N}$ no solo, uma vez que os aminoácidos, em grande parte, são facilmentehidrolisados e, posteriormente, desaminados por microrganismos heterotróficos (Beck, 1983, citado por Mengel, 1996), produzindo amônio como substrato do processo de nitrificação (M engel, 1996). Esta seria uma das explicações para a ocorrência de teores mais elevados de NPM e maior percentagem do $\mathrm{N}$ total fazendo parte da biomassa microbiana nos tratamentos com adubos verdes no inverno.

Diferenças significativas entre as profundidades de amostragem foram detectadas em todos os tratamentos, exceto nos tratamentos ondese utilizou o sistema convencional de cultivo, envolvendo ou não rotação de culturas (C-Mi-P-So e C-Mi-P, respectivamente). O uso do sistema plantio direto envolvendo ou não rotação de culturas (D-Mi-P-So e $\mathrm{D}-\mathrm{Mi}-\mathrm{P}$, respectivamente) levou a camada de 0-0,05 m a apresentar valores significativamente maiores que os encontrados na camada de 0,10$0,20 \mathrm{~m}$. O uso do mesmo sistema com cultivo de Crotalaria juncea no inverno anterior levou a comportamento semel hante, adicionando-se o fato dequea camada de 0,05-0,10 m também apresentou valores significativamente maiores que os encontrados para a camada de 0,10-0,20 m. Os valores de $\mathrm{N}$ total na FSA encontrados nos tratamentos com uso de mucuna-preta ( $\mathrm{D}-\mathrm{Mi}$-Mu) e feijão guandu (D-Mi-Gu) no inverno também foram significativamente maiores na camada de 0-0,05 m, em relação às duas camadas inferiores (Figura 3).

A maior parte do $\mathrm{N}$ total do solo encontra-se na fração humificada da matéria orgânica. Subdividindo esta fração nas suas subfrações (Schnitzer, 1982), verificou-se que a maior parte do $\mathrm{N}$ total presente na matéria húmica foi encontradona humina, a mais estável dentre as três frações, seguida do AF e AH, nas três profundidades (Quadro 4). Tal comportamento também foi observado por outros autores (Albertini, 1983; Nascimento et al., 1988; Pizauro J r \& Melo, 1995), porém, em relação ao teor de carbono total nestas frações da matéria orgânica.

Em estudos de carbono nas frações da matéria orgânica, a relação AH/AF (Figura 4) éum índice ou relação de humificação (I nbar et al., 1990; Pizauro J r \& Melo, 1995). Partindo do princípio de que a redução nos teores de carbono em qualquer uma destas frações via microrganismo só é possível com a presença de nitrogênio, teoricamente esta relação se aplicaria também neste estudo, indicando a predominância de processos de polimerização quando o val or desteíndiceé mais el evado, tal como ocorreu no D-Mi-P, que também apresentou baixa percentagem de $\mathrm{N}$ no AF na camada de 0-0,05 m.

Também usada em estudos de dinâmica de carbono no solo é a relação AF/HN (Figura 5) que indica o sentido do equilíbrio da transformação direta entre as frações (Pizauro J r \& Melo, 1995). Com base neste conceito, poder-se-ia se esperar a ocorrência de processos que estejam levando à 
polimerização no sentido do $A F$ para a $H N$, no tratamento D-Mi-P, na camada de 0-0,05 m, pelo baixo valor encontrado da relação $\mathrm{AF} / \mathrm{HN}$ neste tratamento. Ressalta-se que esta observação foi mais marcante nos tratamentos com plantio direto e pousio no inverno, com ou sem rotação de culturas, tendo esse índice, nas camadas mais profundas, apresentado val or bem superior.

\section{Nitrogênio total nas folhas de milho}

Segundo Trani et al. (1983), o teor total de nitrogênio na fol ha do milho, por ocasião da diagnose foliar, considerado crítico, situa-se próximo de
$30,0 \mathrm{~g} \mathrm{~kg}^{-1}$. Observaram-seacréscimos significativos na absorção de nitrogênio pelas plantas de milho. Nos tratamentos onde se cultivou o milho no sistema de semeadura convencional (C-Mi-P e C-Mi-P-So), os valores encontrados foram maiores $(55,20 \mathrm{e}$ $54,47 \mathrm{mg} \mathrm{kg}^{-1}$, respectivamente), embora tenham sido não-significativos em relação aos dos demais tratamentos. Todos os valores observados foram bem superiores ao nível crítico para a cultura e aos encontrados nestes mesmos tratamentos até o ano agrícola 1995/96 (Souza, 1996), quandoa maior parte dos valores situou-se próximo ou abaixo do nível crítico proposto por Trani et al. (1983).

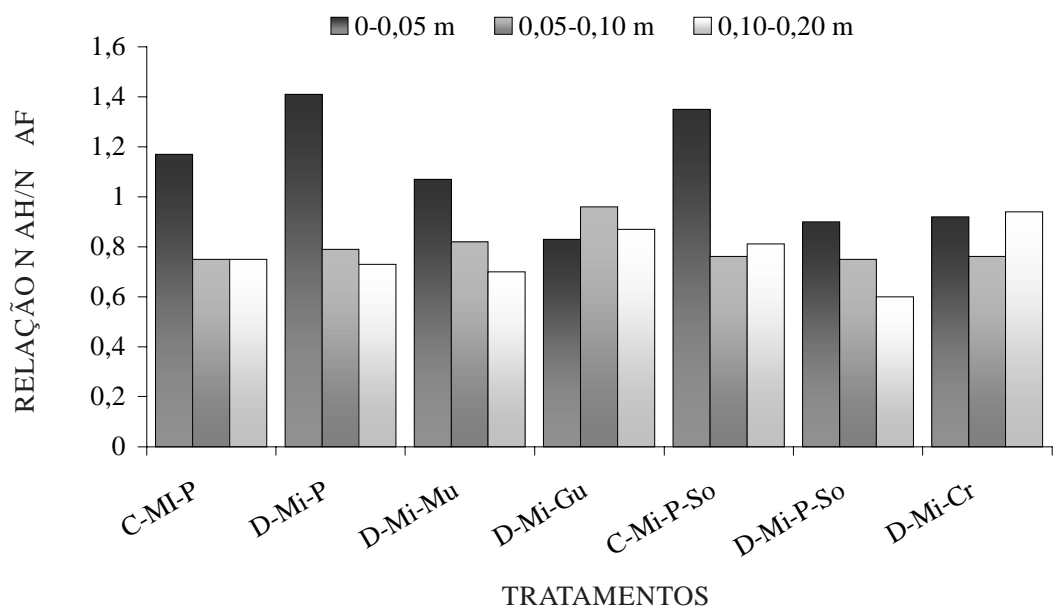

Figura 4. Relação entre o $\mathbf{N}$ total no ácido húmico e $\mathbf{N}$ total no ácido fúlvico (AH/AF) em um Latossolo Roxo cultivado com diferentes sistemas de produção por seis anos consecutivos. C = sistema de semeadura convencional; $\mathrm{D}=$ sistema de plantio direto; $\mathrm{Mi}=$ milho semeado no verão; So $=$ soja semeada no verão; $P$ = pousio no inverno; $M u$ = semeadura de mucuna-preta no inverno; $\mathrm{Gu}=$ semeadura de feijão guandu no inverno; $\mathrm{Cr}=$ semeadura de Crotalaria juncea no inverno.

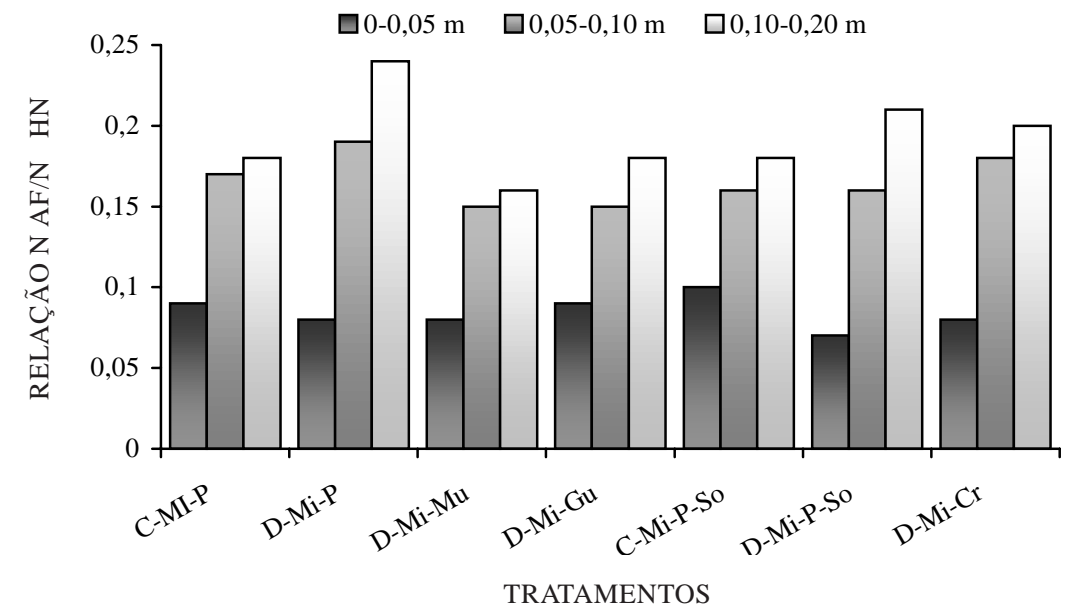

Figura 5. Relação entre o $\mathbf{N}$ total no ácido fúlvico e $\mathbf{N}$ total na humina (AF/HN) em um Latossolo Roxo cultivado com diferentes sistemas de produção por seis anos consecutivos. $C=$ sistema de semeadura convencional; $\mathrm{D}=$ sistema de plantio direto; $\mathrm{Mi}=$ milho semeado no verão; So $=$ soja semeada no verão; $\mathbf{P}=$ pousio no inverno; $M u$ = semeadura de mucuna-preta no inverno; $\mathbf{G u}=$ semeadura de feijão guandu no inverno; $\mathrm{Cr}=$ semeadura de Crotalaria juncea no inverno. 


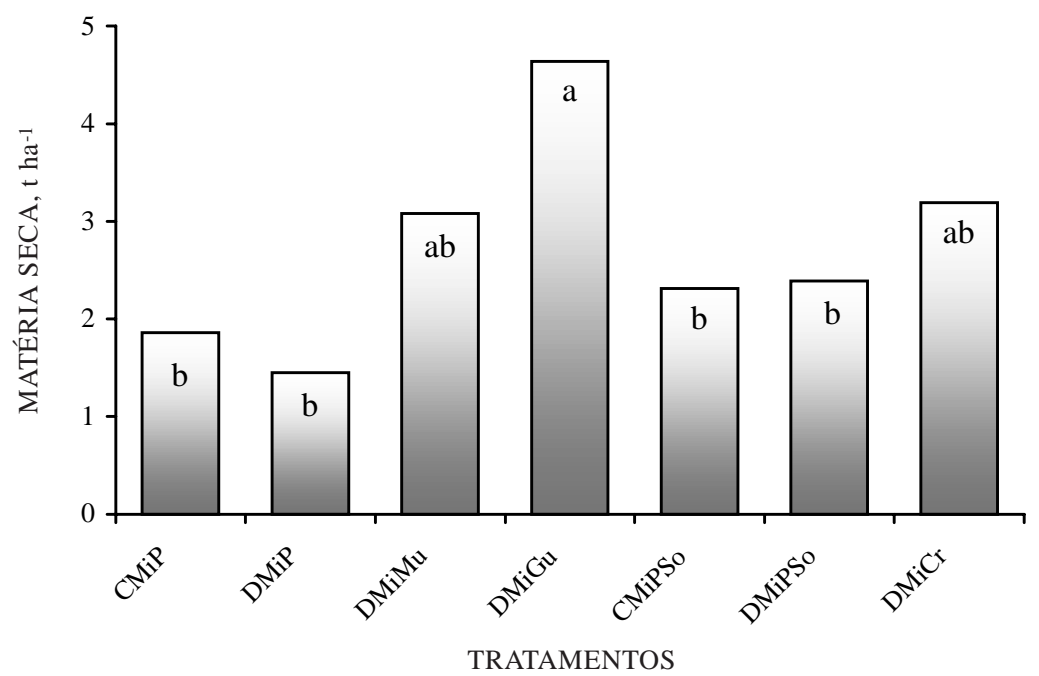

Figura 6. Valores de matéria seca produzida, durante o inverno de 1996, pelos adubos verdes e plantas daninhas em um Latossolo Roxo cultivado com diferentes sistemas de produção por seis anos consecutivos. Médias seguidas de mesma letra não diferem significativamente entre si. C = sistema de semeadura convencional; $\mathrm{D}=$ sistema de plantio direto; $\mathrm{Mi}=$ milho semeado no verão; So = soja semeada no verão; $\mathbf{P}=$ pousio no inverno; $\mathrm{Mu}=$ semeadura de mucuna-preta no inverno; $\mathrm{Gu}=$ semeadura de feijão guandu no inverno; $\mathrm{Cr}=$ semeadura de Crotalaria juncea no inverno.

\section{Culturas de inverno}

Os valores de matéria seca produzida pelas plantas de inverno encontram-se na figura 6. Observa-se que a maior quantidade de material vegetal foi produzida nos tratamentos com plantas de adubo verde (D-Mi-Mu, D-Mi-Gu e D-Mi-Cr).

Embora as plantas utilizadas no ensaio não tenham-seadaptado, de forma satisfatória, ao cultivo após a colheita do milho (fevereiro-abril), tanto a mucuna-preta (representou $56,82 \%$ da MS produzida pelo adubo verde mais invasoras) como o feijão guandu $(66,38 \%$ da MS produzida pel o adubo verde mais invasoras) sobressaíram-se em relação às plantas daninhas, mais agressivas e adaptadas ao ambiente. A adição de seus resíduos ao solo com compostos facilmente hidrolisáveis parece ter exercido efeitos benéficos sobre o NPM e sobre o $\mathrm{N}$ total na FSA na camada de 0-0,05 m, provavelmente pela reprodução de um ambiente mais adequado à atividade microbiana no solo (Lourenço et al., 1993).

\section{CONCLUSÕES}

1. O sistema de semeadura convencional de cultivo apresentou menor teor de $\mathrm{N}$ total na fração solúvel em água e disponibilizou maiores quantidades de $\mathrm{N}-\mathrm{NO}_{3}{ }^{-}$na camada superficial do solo.
2. A mudança do sistema de semeadura convencional para semeadura direta causou el evação na quantidade de nitrogênio potencialmente mineralizável em mais de $80 \%$ (com pousio no inverno) e quase $50 \%$, quando da adoção de rotação de culturas entre o milho e a soja.

3. Os maiores valores de $\mathrm{N}$ da biomassa microbiana ocorreram quando se utilizaram plantas de adubo verde no inverno.

4. A maior parte do $\mathrm{N}$ total do solo incorporou-se às frações da matéria orgânica do solo, predominantementena $\mathrm{HN}$.

\section{LITE RATURA CITADA}

ALBERTINI, P.E.G. E feito da adição de resíduos das culturas de Sorghum bicolor (L.) Moench e Dolichos Iablab L. sobre o carbono e o nitrogênio de frações da matéria orgânica de um Latossolo Roxo. J aboticabal, Universidade Estadual Paulista, 1983. 118p. (Tese de Mestrado)

ALVES, G.D.; SAMPAIO, E.V.S.B.; SALCEDO, I.H. \& SILVA, V.M. Potencial de mineralização de $\mathrm{N}$ e de $\mathrm{C}$ em vinte solos de Pernambuco. R. Bras. Ci. Solo, 23:245-256, 1999.

AMADO, T.J.C.; MIELNICZUK, J .; FERNANDES, S.B.V. \& BAYER, C. Culturas de cobertura, acúmulo de nitrogênio total no solo e produtividade do milho. R. Bras. Ci. Solo, 23:679-686, 1999.

ANDERSON, J.P.E. \& DOMSCH, K.H. Quantities of plant nutrients in the microbial biomass of selected soils. Soil Sci., 130:211-216, 1980. 
BREMNER, J .M. \& KEENEY, D.R. Steam-distillation methods for determination ammonium, nitrate and nitrite. In: BLACK, C.A., ed. Methods of soil analysis. 2.ed. Madison, American Society of Agronomy, 1965. 1572p. (Agronomy, 9)

BROOKES, P.C.; LANDMAN, A.; PUDEN, G. \& J ENKINSON, D.S. Chloroform fumigation and the release of soil nitrogen: a rapid direct extraction method to measure microbial biomass nitrogen in soil. Soil Biol. Biochem.,17:837-842, 1985.

DUARTE, A.P. Calagem esistemas derotação de culturas: efeitos nas características e propriedades da matéria orgânica do solo. J aboticabal, Universidade Estadual Paulista, 1994. 165p. (Tese de Mestrado)

INBAR, Y.; CHEN, Y. \& HADAR, Y. Humic substances formed during the compositing organic matter. Soil Sci. Soc. Am. J ., 54:1316-1323, 1990.

KEENEY, R.C. Nitrogen availability indices. In: BLACK, C.A., ed. Methods of soil analysis. Madison, American Society of Agronomy, 1982. p.711-733. (Agronomy, 9)

LOURENÇO, A.J .; MATSUI, E.; DELISTOIANOV, J .; BOIN, C. \& BORTOLETO, O. Efeitos de leguminosas tropicais na matéria orgânica do solo e na produtividade do sorgo. R. Bras. Ci. Solo, 17:263-268, 1993.

MALAVOLTA, E.; VITTI, G.C. \& OLIVEIRA, S.A. Metodologia para análise de elementos em material vegetal. In: MALAVOLTA, E.; VITTI, G.C. \& OLIVEIRA, S.A., eds. Avaliação do estado nutricional das plantas: princípios e aplicações. 2.ed. Piracicaba, Associação Brasileira para Pesquisa da Potassa e do Fosfato, 1997. p.231-308.

MELO, W.J . Dinâmica das formas de carbono e de nitrogênio em um Latossolo Roxo cultivado com Sorghum bicolor ( $L$ ) Moench e com Dolichos Iablab $L$, isoladamente, ou em cultura intercalada. J aboticabal, Universidade Estadual Paulista, 1977. 118p. (Tese de Livre Docência).

MENGEL, K. Turnover of organic nitrogen in soils and its availability to crops. Plant Soil, 181:83-93, 1996.

NASCIMENTO, V.M.; MELO, W.J . \& NEPTUNE, A.M.L. Efeitos da rotação de culturas sobre as frações da matéria orgânica de um Latossolo Roxo sob vegetação de cerrado. Científica, 16:13-19, 1988.

PAUL, E.A. \& CLARK, F.E. Soil microbiology and biochemistry. London, Academic Press, 1989. 273p.
PIMENTEL GOMES, F. Estatística experimental. 8.ed. SãoPaulo, Nobel, 1978. p.295-322.

PIZAURO J r., J .M. \& MELO, W.J . Influência da incorporação da parte aérea de sorgo ou lablabe nas frações da matéria orgânica de um latossol o vermel ho escuro. R. Bras. Ci. Solo, 19:95-103, 1995.

RAIJ , B. van; SILVA, N.M.; BATAGLIA, O.C.; QUAGGIO, J .A.; HIROCE, R.; CANTARELLA, H.; BELLINAZZI J UNIOR, R.; DECHEN, A.R. \& TRANI, P.E. Recomendações de adubação e calagem para o Estado de São Paulo. Campinas, Instituto Agronômico, 1985. p.2-11 (Boletim Técnico, 100)

SALCEDO, I.H.; SAMPAIO; E.V.S.B. \& ALVES, G.D. Mineralização do carbono e do nitrogênio em solo cultivado com cana de açúcar. R. Bras. Ci. Solo, 9:33-38, 1985.

SCHNIER, H.F.; DE DATTA S.K. \& MENGEL, K. Dynamics of ${ }^{15} \mathrm{~N}$-labled ammonium sulfate in various inorganic and organic soil fractions of wetland ricesoils. Biol. Fertil. Soils, 4:171-177, 1987.

SCHNITZER, M. Organic matter characterization. In: PAGE, A.L., ed. Methods of soil analysis, 2.ed. Madison, American Society of Agronomy, 1982. p.581-594. (Agronomy, 9)

SOUZA, W.J . O. Influência de sistemas de produção, envolvendo semeadura direta e convencional, nas formas de $\mathrm{C}$ e $\mathrm{N}$ do solo e no $\mathrm{N}$ foliar do milho. J aboticabal, Universidade Estadual Paulista, 1996. 83p. (Trabalho apresentado à Faculdade de Ciências Agrárias e Veterinárias, UNESP, Campus de J aboticabal, para graduação em Agronomia)

STEVENSON, F.J . Cycles of soil: carbon, nitrogen, phosphorus, sulfur, micronutrients. New York, J ohn Wiley \& Sons, 1985. p.167-178.

TATE III, R.L. Humic and fulvic acids: formation and decomposition. In: TATE III, R.L., ed. Soil organic matter: biological and ecological effects. New York, J ohn Wiley \& Sons, 1987. p.147-164.

TRANI, P.E.; HIROCE, R. \& BATAGLIA, O.C. Análise foliar: amostragem e interpretação. Campinas, Fundação Cargill, 1983.18p.

VANCE, E.D.; BROOKES, P.C. \& JENKINSON, D.S. An extraction method for measurement soil microbial biomass - C. Soil Biol. Biochem., 19:703-707, 1987.

VARGAS, L.K. \& SCHOLLES, D. Nitrogênio da biomassa microbiana, em solo sob diferentes sistemas de manejo, estimado por métodos de fumigação. R. Bras. Ci. Solo, 22:411-417, 1998. 